\title{
\begin{tabular}{|l|l|l|l|l|}
\hline $\mathrm{M}$ & $\mathrm{R}$ & $\mathrm{S}$ & Internet Journal of & Nitride Semiconductor Research \\
\hline
\end{tabular}
}

Volume 1, Article 29

\section{GaN Based p-n Structures Grown on SiC Substrates}

\author{
V.A. Dmitriev \\ Cree Research, Inc. \\ This article was received on J une 4, 1996 and accepted on October 30, 1996.
}

\begin{abstract}
Wide band gap nitrides(InN, GaN, AIN) have been considered promising optoelectronics materials for many years [1]. Recently two main technological problems in the nitrides were overcome: (1)high quality layers has been grown on both sapphire and SiC substrates and(2) p-type GaN and AlGaN material has been obtained. These achievements resulted in the fabrication of bright light emitters in the violet, blue and green spectral regions [2].First injection laser has been demonstrated [3]. This paper reviews results obtained over the last few years on nitride $p-n$ junctions, particularly on GaN based p-n junctions grown on SiC substrates. We will consider GaN p-n junctions, AlGaN p-n junctions, GaN and AlGaN p-i-n structures, and, finally, GaN/SiC p-n structures.
\end{abstract}

\section{Introduction}

For all structures discussed bellow $6 \mathrm{H}-\mathrm{SiC}$ and $4 \mathrm{H}-\mathrm{SiC}$ wafers were used as substrates. All structures except $\mathrm{GaN} / \mathrm{SiC}$ heterostructures were grown by metal organic chemical vapor epitaxy (MOCVD) [4]. Hydride vapor phase epitaxy (HVPE) [5] was employed for GaN/SiC p-n heterojunction fabrication. Usually GaN was deposited on (0001)Si face of the substrate (the p-n junction plane was perpendicular to the c crystal axis). In MOCVD grown structures, $\mathrm{Si}$ and $\mathrm{Mg}$ were used as donor and acceptor impurities, respectively. $\mathrm{Ni}$, Ti or Pd metals was employed to form ohmic contact top-GaN [6] and Al, Ni or Ti/Ni ohmic contacts were formed to n-GaN [7]. Mesa structures were formed by reactive ion etching (RIE) [8].

\section{GaN p-n junctions}

In this section we will discuss characteristics of GaN p-n homojunctions. The first GaN p-n junction was reported in 1989 [9]. Since, significant progress has been achieved on fabrication of GaN p-n structures [10] [11] [12] [13] [14] [15][16]. However, published information on the main properties of these junctions(i.e., impurity distribution in the junction, built-in voltage, current flow mechanism, breakdown characteristics) still is very limited. We will describe two types of the junctions fabricated on silicon carbide substrates: (1) linear graded p-n junctions and (2) abrupt p-n junctions. Mesa structure diameter ranged from 100 to $300 \mu \mathrm{m}$. The $p-n$ junctions were characterised in terms of capacitance-voltage (C-V) and current-voltage (I-V) characteristics. The position of the $p-n$ junction in the structure was determined by electron beam induced current. The concentration of electrically active uncompensated impurities, $\left[\mathrm{N}_{\mathrm{d}}-\mathrm{N}_{\mathrm{a}}\right]$, was measured using C-V characteristic of GaN p-n junction or Shottky barrier.

\subsection{Linearly graded GaN p-n junctions}

GaN layers of $\mathrm{n}$ - and $\mathrm{p}$-type were grown subsequently in the same epitaxial run (Figure 1 ). A typical thickness for $\mathrm{n}$ and p-layer was $\sim 2 \mu \mathrm{m}$ and $\sim 0.5 \mu \mathrm{m}$, respectively. The concentration $\mathrm{N}_{d}-\mathrm{N}_{\mathrm{a}}$ in $\mathrm{n}$-layer was $\sim 2 \times 10^{18} \mathrm{~cm}^{-3} \cdot \mathrm{N}_{\mathrm{a}}-\mathrm{N}_{\mathrm{d}}$ concentration in $\mathrm{p}-\mathrm{GaN}$ layer ranging from $3 \times 10^{17}$ to $1 \times 10^{18} \mathrm{~cm}^{-3}$. At the surface $\mathrm{N}_{\mathrm{a}}-\mathrm{N}_{d}$ value was increased up to $\sim 10^{19} \mathrm{~cm}^{-3}$.

\subsubsection{C-V characteristics}


$\mathrm{C}-\mathrm{V}$ characteristics of the diodes were linear when plotted in $\mathrm{V}-\mathrm{C}^{-3}$ coordinates. This indicates that the $\mathrm{p}-\mathrm{n}$ junctions had a linear impurity distribution. The built-in violate, $\mathrm{V}_{\mathrm{bi}}$, determined by $\mathrm{C}-\mathrm{V}$ measurements ranged from 2.2 to 2.6

$V$. The impurity gradient $(\alpha)$ in the $p-n$ junction was determined from C-V data to be from $2 \times 10^{22}$ to $2 \times 10^{23} \mathrm{~cm}^{-4}$ for different samples.

\subsubsection{Forward I-V characteristics}

The I-V characteristics were measured for current densities from $10^{-10}$ to $10 \mathrm{~A} / \mathrm{cm}^{2}$ in the temperature range from 200 to $600 \mathrm{~K}$. At a forward voltage less than $\sim 2.2 \mathrm{~V}$, the forward current density, J, was an exponential function of applied voltage (Figure 2):

$$
\mathrm{J}=\mathrm{J}_{0} \exp (q \mathrm{~V} / \mathrm{nkT}) \text {, }
$$

where $\mathrm{J}_{\mathrm{O}}$ is the saturation current density and $\mathrm{n}$ is the ideality factor. In the temperature range from 200 to $400 \mathrm{~K}$ ideality factor $n$ was dependent on temperature and ranged from 7 to 2.4 . It means that in this temperature range current flow mechanism cannot be explained by a classical model for carrier recombination in a space charge region [17]. At temperatures higher than $450 \mathrm{~K}, \mathrm{n}$ is equal to $\sim 2$ and is independent of temperature. In this high temperature region, the saturation current density $J_{0}$ showed an exponential dependence on temperature(Figure 3):

$$
J_{0}=J_{0} * \exp \left(-E_{a} / k T\right)
$$

where $\mathrm{J}_{0}{ }^{*}$ is the pre-exponential factor and $\mathrm{E}_{\mathrm{a}}$ is an activation energy being close to half of the GaN band gap.

Thus, we may conclude that for the temperature range from 450 to $600 \mathrm{~K}$ the current flow mechanism in the GaN p-n junctions may be described by the Sah - Noyce -Shockley model for carrier recombination in a space charge region [18]. At high current densities the I-V characteristics were determined by contact resistance of the contact top-GaN.

\subsubsection{Reverse I-V characteristics}

The reverse I-V characteristics showed abrupt breakdown at voltage ranging from 40 to $150 \mathrm{~V}$. Breakdown voltage, $\mathrm{V}_{\mathrm{b}}$, was determined as the voltage at which an abrupt change in the reverse I-V characteristics occurred (Figure 4). The breakdown had a microplasmic nature. Microplasms were seen by direct observation. At reverse voltages less than breakdown voltage $\left(\mathrm{V}<0.9 \times \mathrm{V}_{\mathrm{b}}\right)$, the leakage current at room temperature was less than $10^{-6} \mathrm{~A}\left(\mathrm{~J}=10^{-2} \mathrm{~A} / \mathrm{cm}\right.$ 2).

It was found [16] that the strength of the electric breakdown field for the GaN p-n junctions ranged from 1.5 to 3 $\mathrm{MV} / \mathrm{cm}$. This value is approximately 4 times higher than the maximum breakdown field for a linearly graded GaAs $p-n$ junction at the same impurity gradient.

As was mentioned before, we did not see uniform electric breakdown. This means that the obtained $E$ values do not represent the maximum strength of the electric breakdown field, $E_{m}$, in $\mathrm{GaN}$, but may be used to estimate a lower limit of $E_{m}\left(E_{m}>E\right)$. The exact value of $E_{m}$ for $G a N$ - $n$ junctions must be measured on $p$-n structures having uniform breakdown over the entire $p-n$ junction area.

Breakdown voltage increases with temperature. The temperature coefficient of the breakdown voltage was measured to be $\sim 2 \times 10^{-4} \mathrm{~K}^{-1}$ for a sample having $\alpha=3 \times 10^{22} \mathrm{~cm}^{-4}$.

\subsection{Abrupt GaN p-n junctions}

Another type of GaN p-n structures was grown in two different epitaxial runs. In the first run, p-GaN 1.5um thick layer having $\mathrm{N}_{\mathrm{a}}-\mathrm{N}_{\mathrm{d}}$ concentration of $\sim 10^{19} \mathrm{~cm}^{-3}$ was grown. Then, in the second run $\mathrm{n}-\mathrm{n}^{+} \mathrm{GaN}$ structure was deposited. Thickness of the $n$-layer was $0.7 \mu \mathrm{m}$. Thickness of then ${ }^{+}$-layer was about $\sim 0.1 \mu \mathrm{m}$. Surface $\mathrm{N}_{\mathrm{d}}-\mathrm{N}_{\mathrm{a}}$ concentration was $\sim 10^{19} \mathrm{~cm}^{-3}$. Device structure is shown in Figure 5. Mesa diameter was $100 \mu \mathrm{m}$.

\subsubsection{C-V characteristics}


The $\mathrm{C}-\mathrm{V}$ characteristics of the structures were linear then plotted in $\mathrm{V}-\mathrm{C}^{-2}$ coordinates indicating that $\mathrm{p}-\mathrm{n}$ junction was abrupt. The cut-off voltage of the $\mathrm{C}-\mathrm{V}$ characteristics for different samples ranged from 2.7 to $3.5 \mathrm{~V}$ ( $300 \mathrm{~K}$ ).

\subsubsection{I-V characteristics}

In a low current density region $\left(\mathrm{J}<1 \mathrm{~A} / \mathrm{cm}^{2}\right)$, the forward current density was an exponential function of applied voltage and may be described by equation 1 . In the temperature range from 300 to $620 \mathrm{~K}$ ideality factor $n$ was dependent on temperature and ranged from 2.5 to 1.5. The current flow mechanism is under investigation.

At a higher current density $\left(\mathrm{J}>10 \mathrm{~A} / \mathrm{cm}^{2}\right)$ the $\mathrm{I}-\mathrm{V}$ characteristics were determined by resistivity of the $\mathrm{p}-\mathrm{GaN}$ layer. High resistivity of $p$ - GaN is due to relatively low carrier concentration $\left(p \sim 5 \times 10^{17} \mathrm{~cm}^{-3}, 300 \mathrm{~K}\right)$, low carrier mobility $\left(\mu_{\mathrm{p}}\right.$ $\left.\sim 10 \mathrm{~cm}^{2} \mathrm{~V} / \mathrm{s}\right)$, and small thickness of $\mathrm{p}-\mathrm{GaN}$ layer $(\sim 1.5 \mu \mathrm{m})$.

The reverse I-V characteristics showed abrupt breakdown at voltage ranged from 40 to $60 \mathrm{~V}$. This value is a few times less than may be expected for breakdown field measured for linear graded $p-n$ junction and $N_{d}-N_{a}$ concentration in $n-G a N$ layer determined from C-V measurements $\left(N_{d}-N_{a} \sim 10^{17} \mathrm{~cm}^{-3}\right)$. We believe that in this case the $p$-n junction breakdown is due to n-region pinch off. To measure the real breakdown field for abrupt GaN p-n junction the base region of the diode should be thicker or $\mathrm{N}_{\mathrm{d}}-\mathrm{N}_{\mathrm{a}}$ concentration higher.

\subsection{Electroluminescence of GaN p-n junctions}

Electroluminescence (EL) spectra for GaN p-n junctions (Figure 7) usually contained an edge peak at $\sim 365 \mathrm{~nm}$ ( $\mathrm{hv}$ $\sim 3.4 \mathrm{eV}$ ), impurity attributed peaks in the range from 410 to $460 \mathrm{~nm}(2.7-3.0 \mathrm{eV})$, and the so-called "defect" peak at $\sim 550 \mathrm{~nm}(\sim 2.25 \mathrm{eV})$. A detailed description of edge peak properties is given in reference [19]. Depending on growth and doping conditions and on the GaN p-n junction design, each of the peak scan dominate the EL spectrum.

\section{AIGaN p-n junctions}

Moving towards the shorter wavelength region requires the active region of the emitter to have a wider band gap than that for $\mathrm{GaN}\left(\mathrm{E}_{\mathrm{gGaN}} \sim 3.4 \mathrm{eV}\right.$, which corresponds to $\lambda$ of $\left.\sim 365 \mathrm{~nm}\right)$. Here we describe $\mathrm{p}$-n junctions formed inside AlGaN alloys [20].

AlGaN p-n junctions were grown on $6 \mathrm{H}-\mathrm{SiC}$ substrates by MOCVD. Band gap diagram of the $\mathrm{p}-\mathrm{n}$ structure and device structure are schematically shown in Figure 8. First n-GaN layer about $\sim 1.5 \mu$ m thick was grown. After that the p-n homojunction or heterojunction was formed between two layers of AlGaN. Then a p ${ }^{+}$-GaN cap layer $\sim 0.5 \mu \mathrm{m}$ thick was grown. The maximum AIN concentration in AIGaN layers was $\sim 8$ mol.\%. Mesa structures diameter was 300 $\mu \mathrm{m}$. Pd and Al were used as materials for ohmic contacts for p-type and n-type GaN, respectively.

Capacitance-voltage characteristics indicated that these junctions were linearly graded. The built-in voltage was $\mathrm{V}_{\mathrm{bi}}$ $=4-8 \mathrm{~V}$ indicating the existence of a compensated region inside the junction.

The EL spectra of the structures was measured at room temperature. The edge $E L$ peak which position depends on AIN concentration in the structure was detected. We attribute this peak to carrier recombination in one or both AIGaN layers. The dependence of photon energy for the EL edge peak on AIN concentration in the base AIGaN layer (the layer with the smaller AIN concentration in the case of $p$-n heterojunctions) is shown in Figure 9. The minimum

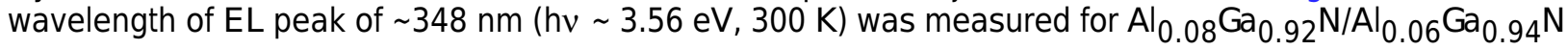

heterostructure.

When the thickness of $\mathrm{n}-\mathrm{AlGaN}$ layer was small $(<0.3 \mu \mathrm{m})$, the EL peak situated at $365 \mathrm{~nm}$ was detected in the spectrum. It was believed that injected carriers may reach the $\mathrm{n}-\mathrm{GaN}$ layer and peak at $365 \mathrm{~nm}$ is attributed to carrier recombination in $\mathrm{n}-\mathrm{GaN}$ region. For the structure having $\mathrm{n}$-AIGaN layer $\sim 0.5 \mu \mathrm{m}$ thick, EL spectra did not contain the edge peak at $\lambda_{\max } \sim 365 \mathrm{~nm}$. It was assumed that in this structure, the $\mathrm{n}$-AlGaN layer is much thicker and carrier recombination is taking place in AlGaN.

\section{GaN and AIGaN p-i-n structures}


Semiconductor $p$-i-n structures are of scientific and practical interest. P-i-n structures may be used in optoelectronics and high-frequency electronics. Along with them being practical, investigation of $p$-i-n structures gives us an understanding of the physics of semiconductor materials.

GaN and AIGaN p-i-n structures were grown by MOCVD on 6H-SiC substrates [21]. For n-type layers doped with Si concentration $\mathrm{N}_{\mathrm{d}}-\mathrm{N}_{\mathrm{a}}$ was about $\sim 1 \times 10^{18} \mathrm{~cm}^{-3}$. For $\mathrm{p}$-type layers doped with $\mathrm{Mg}$ concentration $\mathrm{N}_{\mathrm{a}}-\mathrm{N}_{\mathrm{d}}$ ranged from $3 \times 10^{17}$ to $\sim 1 \times 10^{19} \mathrm{~cm}^{-3}$. First $\sim 2 \mu \mathrm{m}$ thick GaN layer with $\mathrm{N}_{\mathrm{d}}-\mathrm{N}_{\mathrm{a}} \sim 1 \times 10^{18} \mathrm{~cm}^{-3}$ was grown. Then $\mathrm{GaN}$ or $\mathrm{Al}_{0.08} \mathrm{Ga}_{0.92} \mathrm{~N}$ p-n homojunctions were formed. On the top of the $p-n$ junctions a $0.5 \mu \mathrm{m}$ thick cap $\mathrm{p}^{+} \mathrm{GaN}$ layer was grown atop the $\mathrm{p}-\mathrm{n}$ junction. The structures were grown by the way providing formation of a highly compensated i-region between the $\mathrm{n}$ - and $\mathrm{p}$-layers. Mesa structure diameter was $300 \mu \mathrm{m}$. Pd and $\mathrm{Al}$ were used as ohmic contacts for $\mathrm{p}^{+}-\mathrm{GaN}$ and $\mathrm{n}-\mathrm{GaN}$, respectively. A planar device geometry was used (Figure 10).

\subsection{C-V characteristics}

The C-V characteristics of the GaN and AIGaN p-i-n junctions were linear when plotted in $C^{-2}-V$ coordinates. Built-in voltage for the $\mathrm{GaN}$ p-i-n structures determined by the $\mathrm{C}-\mathrm{V}$ measurements ranged from 4 to $7 \mathrm{~V}$. This value is larger than that for a normal GaN p-n junctions doped with Si and $\mathrm{Mg}$. The difference due to an i-region located in the structure. The width of the i-region was found from C-V measurements to be about $0.1 \mu \mathrm{m}$.

\subsection{I-V characteristics}

Typical forward current-voltage(I-V) characteristics of GaN p-i-n structures are shown in Figure 11 . The I-V characteristics contain power-law regions ( $\sim \mathrm{Vb}$, where $\mathrm{b}$ ranged from 1 to 10$)$. At temperatures less than $100 \mathrm{~K}$ and forward voltage of about $15 \mathrm{~V}$, s-shape of forward I-V characteristic was observed. Such current behaviour is typical for $p$-i-n structures. The measured forward I-V characteristics follow the model [22] describing current transport in $\mathrm{p}$-i-n structures with i-regions having deep-level impurities. A single recombination centre is assumed, which, in equilibrium is partially occupied by electrons. Also it is assumed that the capture-cross sections of the recombination centres are different for holes and electrons. The activation energy of these recombination centres was extracted from the temperature dependence of the forward current at fixed voltage. Plots of $\log (\mathrm{I})-1 / \mathrm{T}$ are linear with a slope corresponding to an ionisation energy of $0.146 \mathrm{eV}$ and of $0.191 \mathrm{eV}$ for the GaN and the AlGaN p-i-n structures, respectively.

Reverse I-V characteristics of the $\mathrm{p}$-i-n structures showed abrupt breakdown at voltages ranging from 20 to $90 \mathrm{~V}$. The strength of the breakdown electric field was estimated to be $~ 3 \mathrm{MV} / \mathrm{cm}$ for GaN and AlGaN structures.

To determine parameters of deep centres in the structures the current-transient mode deep-level transient spectroscopy (i-DLTS) was used [23]. Presence of hole traps was detected. The values of the ionisation energy for deep level in $\mathrm{GaN}$ and $\mathrm{Al}_{0.08} \mathrm{Ga}_{0.92} \mathrm{~N} \mathrm{p}$-i-n structures determined by i-DLTS measurements $(0.141 \mathrm{eV}$ for $\mathrm{GaN}$ and $0.207 \mathrm{eV}$ for $\mathrm{AlGaN}$, respectively) are in good agreement with ionisation energy for $\mathrm{Mg}$ acceptor measured using the Hall effect [24].

\section{5. $n-G a N / p-S i C$ heterojunctions}

The direct deposition of GaN on SiC provides one the opportunity to create devices based on GaN/SiC heterojunctions. Recently GaN has been successful grown on SiC substrates without buffer layers by HVPE. The deposition technique was described elsewhere [5]. The thickness of the GaN layers ranged from 0.5 to $2 \mu \mathrm{m}$. GaN growth rate was controlled from 0.02 to $0.4 \mu \mathrm{m} / \mathrm{min}$.

Mesa-structures (150 $\mu \mathrm{m}$ diameter) were formed by RIE (Figure 12). The capacitance-voltage (C-V) characteristics

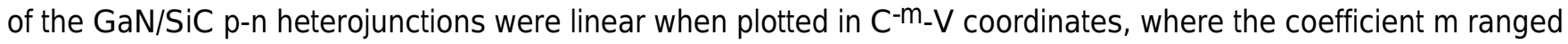
from 2.5 to 2.7. The cut-off voltage of $\mathrm{C}-\mathrm{V}$ characteristics was about $2.0 \mathrm{~V}$. This value is close to the built-in potential for $\mathrm{n}-\mathrm{GaN} / \mathrm{p}-6 \mathrm{H}-\mathrm{SiC}$ heterojunction estimated using Anderson's model and found to be $\sim 2.2 \mathrm{~V}$ [25].

The structures showed good rectifying characteristics for GaN/SiC p-n heterojunctions (Figure 13). Breakdown voltage ranged from 15 to $100 \mathrm{~V}$. The turn on voltage of forward I-V characteristics was $\sim 2 \mathrm{~V}$ which corresponds to built-in potential. It should be note that the value of cut-off voltage determined from C-V measurements is close to the turn on voltage for forward I-V characteristics. 


\section{References}

[1] H. Morkoc, S. Strite, G. B. Gao, M. E. Lin, B. Sverdlov, M. Burns , J. Appl. Phys. 76, 1363-1398 (1994).

[2] Shuji Nakamura, Masayuki Senoh, Naruhito Iwasa, Shin-ichi Nagahama , Appl. Phys. Lett. 67, 1868-1870 (1995).

[3] S. Nakamura, M. Senoh, S. Nagahama, N. Iwasa, T. Yamada, T. Matsushita, H. Kiyoku, Y. Sugimoto, J pn. J. Appl. Phys. 35, L217-L220 (1996).

[4] VA Dmitriev, KG Irvine, J A Edmond, et al., Inst. Phys. Conf. Ser. 141, 497-502 (1995).

[5] YuV Melnik, IP Nikitina, AS Zubrilov, AA Sitnikova, YuG Musikhin, VA Dmitriev, Inst. Phys. Conf. Ser. 142, 863-866 (1996).

[6] K.V. Vassilevski, M.G. Rastegaeva, A.I. Babanin, I.P. Nikitina, V.A. Dmitriev, MRS Internet J. Nitride Semicond. Res. 1, 38 (1996).

[7] KV Vassilevski, MG Rastegaeva, Al Babanin, IP Nikitina, VA Dmitriev, unpublished (1996).

[8] KV Vassilevski, VE Sizov, Al Babanin, YuV Melnik, AS Zubrilov, Inst. Phys. Conf. Ser. 142, 1027-1030 (1996).

[9] H. Amano, M. Kito, K. Hiramatsu, I. Akasaki, Inst. Phys. Conf. Ser. 106, 725 (1990).

[10] I Akasaki, H Amano, J. Electrochem.Soc. 141, 2266-2271 (1994).

[11] S. Nakamura, T. Mukai, M. Senoh, J pn. J. Appl. Phys. 30, L1998 (1991).

[12] Barbara Goldenberg, J. David Zook, Robert J. Ulmer , Appl. Phys. Lett. 62, 381-383 (1993).

[13] M. Asif Khan, Q. Chen, R. A. Skogman, J. N. Kuznia , Appl. Phys. Lett. 66, 2046-2047 (1995).

[14] R. J. Molnar, R. Singh, T. D. Moustakas, Appl. Phys. Lett. 66, 268-270 (1995).

[15] VA Dmitriev, KG Irvine, J A Edmond, CH Carter, NI Kuznetsov, AS Zubrilov, EV Kalinina, DV Tsvetkov, Inst. Phys. Conf. Ser. 142, 1019-1022 (1996).

[16] V. A. Dmitriev, K. G. Irvine, C. H. Carter, J r., N. I. Kuznetsov, E. V. Kalinina , Appl. Phys. Lett. 68, 229-231 (1996).

[17] SM Sze, Physics of Semiconductor Devices (Wiley, New York, 1981) .

[18] CT Sah, RN Noyce, W Shockleyin Proceedings of IRE, v.45(9), , (1957) 1228.

[19] AS Zubrilov, DV Tsvetkov, VI Nikolaev, VA Soloviev, VA Dmitriev, Inst. Phys. Conf. Ser. 142, 1003-1006 (1996).

[20] V. A. Dmitriev, K. Irvine, C. H. Carter, J r., A. S. Zubrilov, D. V. Tsvetkov , Appl. Phys. Lett. 67, 115-117 (1995).

[21] NI Kuznetsov, VA Dmitrievin Technical Digest of the Int. Conf. of SiC and Related Materials, , (Kyoto University, Kyoto, 1995) 272-273.

[22] KL Ashley, AG Milnes, J. Appl. Phys. 35, 369 (1994).

[23] NI Kuznetsov, Semiconductors 27, 925-928 (1993).

[24] T. Tanaka, A. Watanabe, H. Amano, Y. Kobayashi, I. Akasaki, S. Yamazaki, M. Koike , Appl. Phys. Lett. 65, 
[25] NI Kuznetsov, AE Gubenco, AE Nikolaev, YuV Melnik, MN Blashenkov, IP Nikitina, VA Dmitriev, Mater. Sci. Eng. B 46, 74-78 (1997).
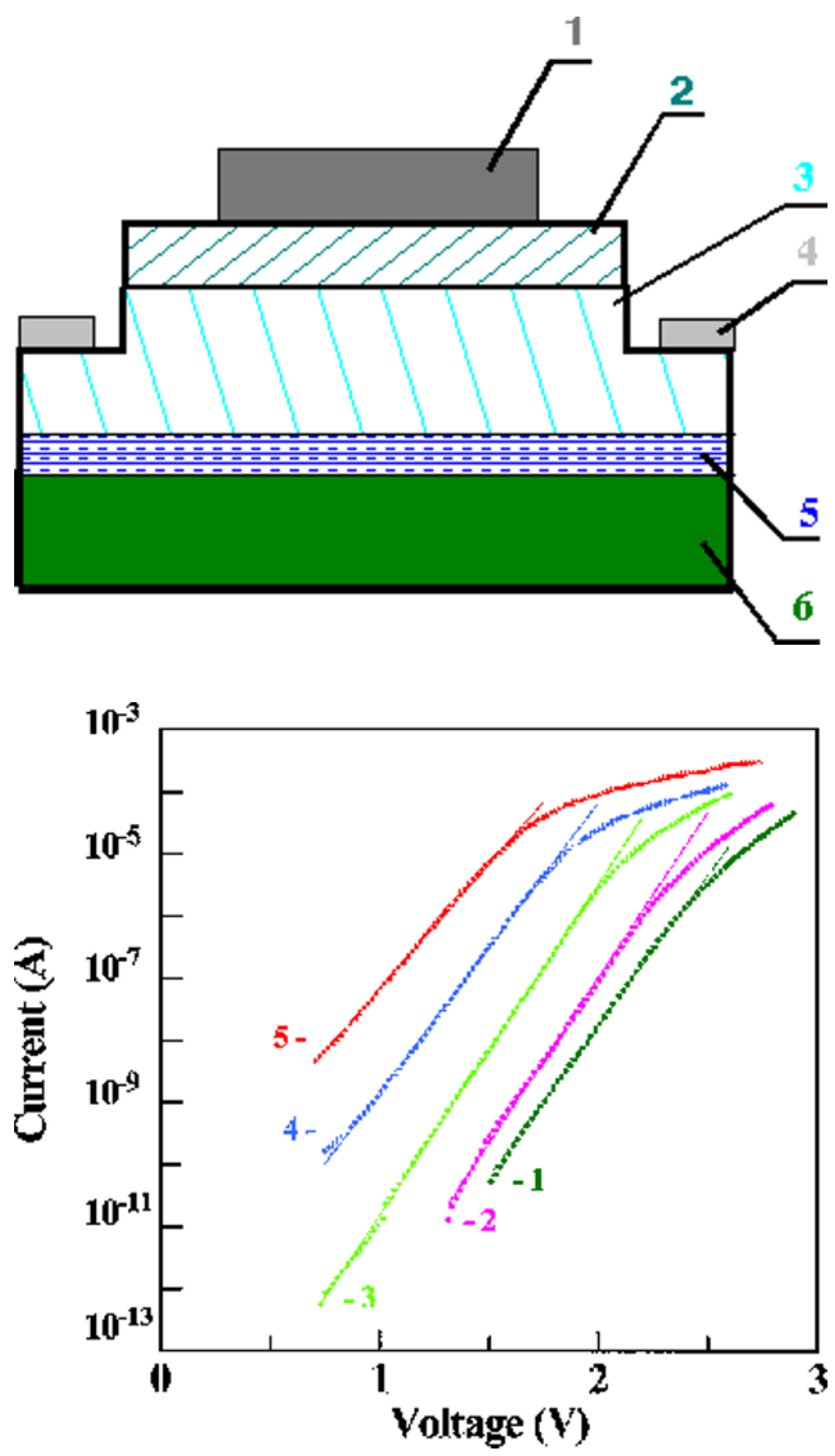

Figure 1. Schematic drawings of the GaN p- $n$ homojunction: 1 - Pd contact to p-GaN, 2 - p-GaN layer, 3 - n-GaN layer, 4- Al contact to n-GaN, 5 buffer layer, 6 - $6 \mathrm{H}-\mathrm{SiC}$ substrate.

Figure 2. Forward I-V characteristics for linearly graded GaN p- n junction: 1 - 250 K, 2 - 300 K, 3 $400 \mathrm{~K}, 4-500 \mathrm{~K}, 5-600 \mathrm{~K}$. 


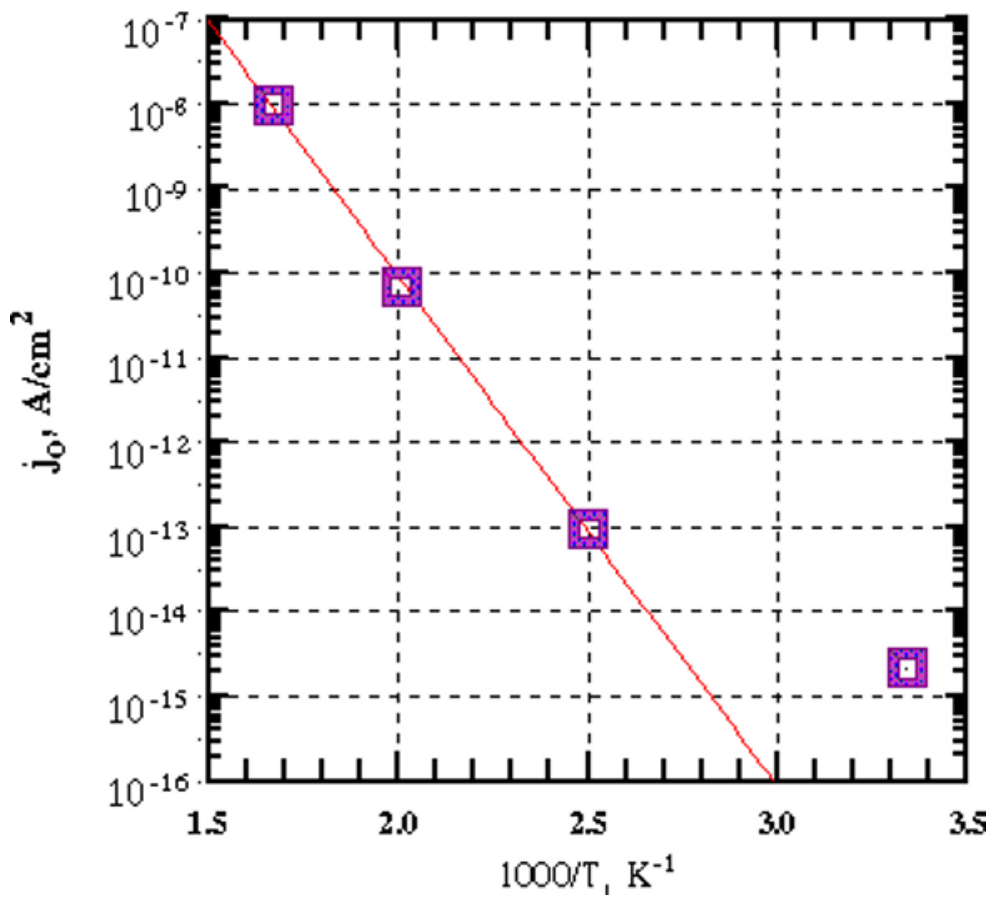

Figure 3. Saturation current for GaN p- $n$ junction as a function of temperature.

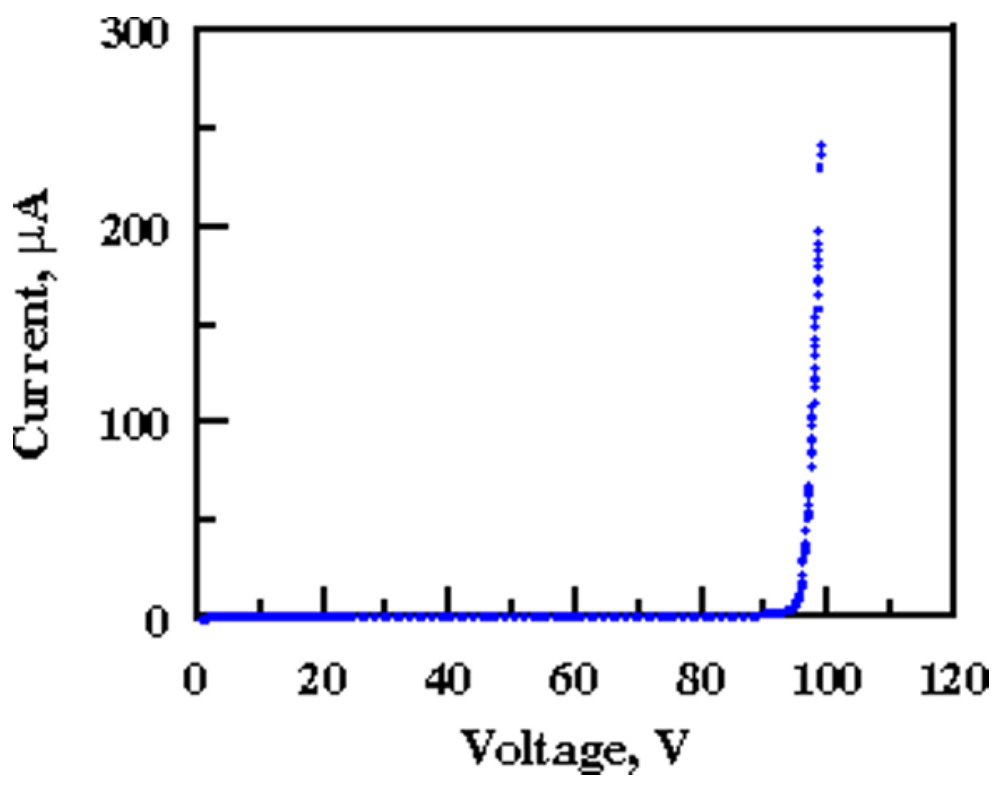

Figure 4. Reverse I-V characteristics for linearly graded GaN p- $n$ junction (300 K). 


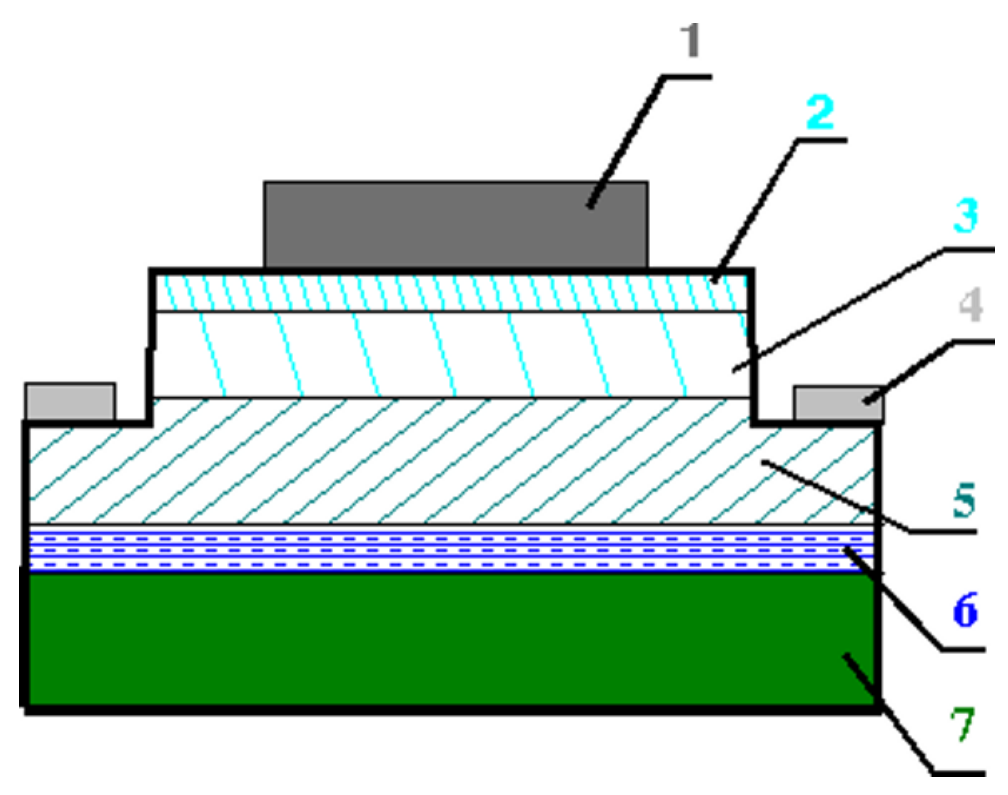

Figure 5. Schematic drawings of the abrupt GaN p- $\mathrm{n}$ homojunction: 1 - Ti/Ni contact to $\mathrm{n}-\mathrm{GaN}, 2$ - $\mathrm{n}$ +-GaN layer, 3 - n-GaN layer, 4 - Ti contact to p-GaN, 5 p-GaN layer, 6 - buffer layer, 7 - 6H-SiC substrate.

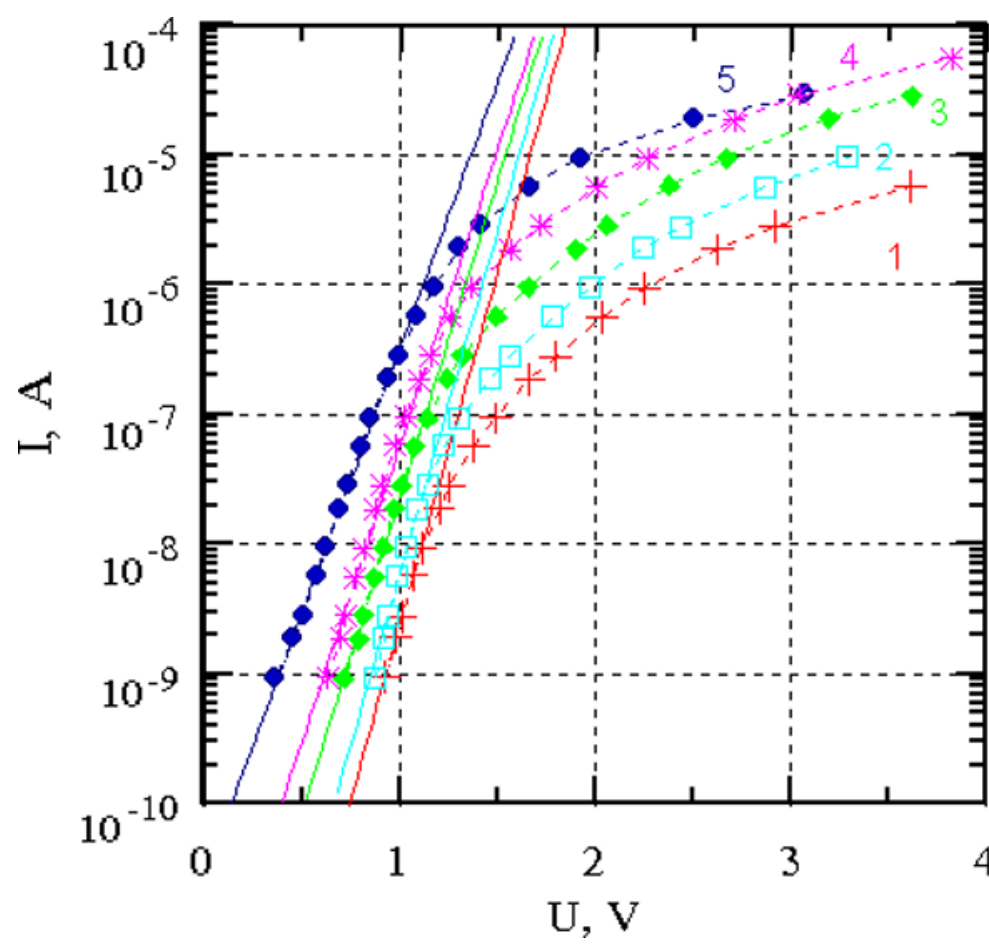

Figure 6. Forward I-V characteristics for $\mathrm{GaN}$ abrupt $p$ - $n$ junction: 1 - 290 K, 2 - 336 K, 3 - 410 $\mathrm{K}, 4-500 \mathrm{~K}, 5-623 \mathrm{~K}$. 


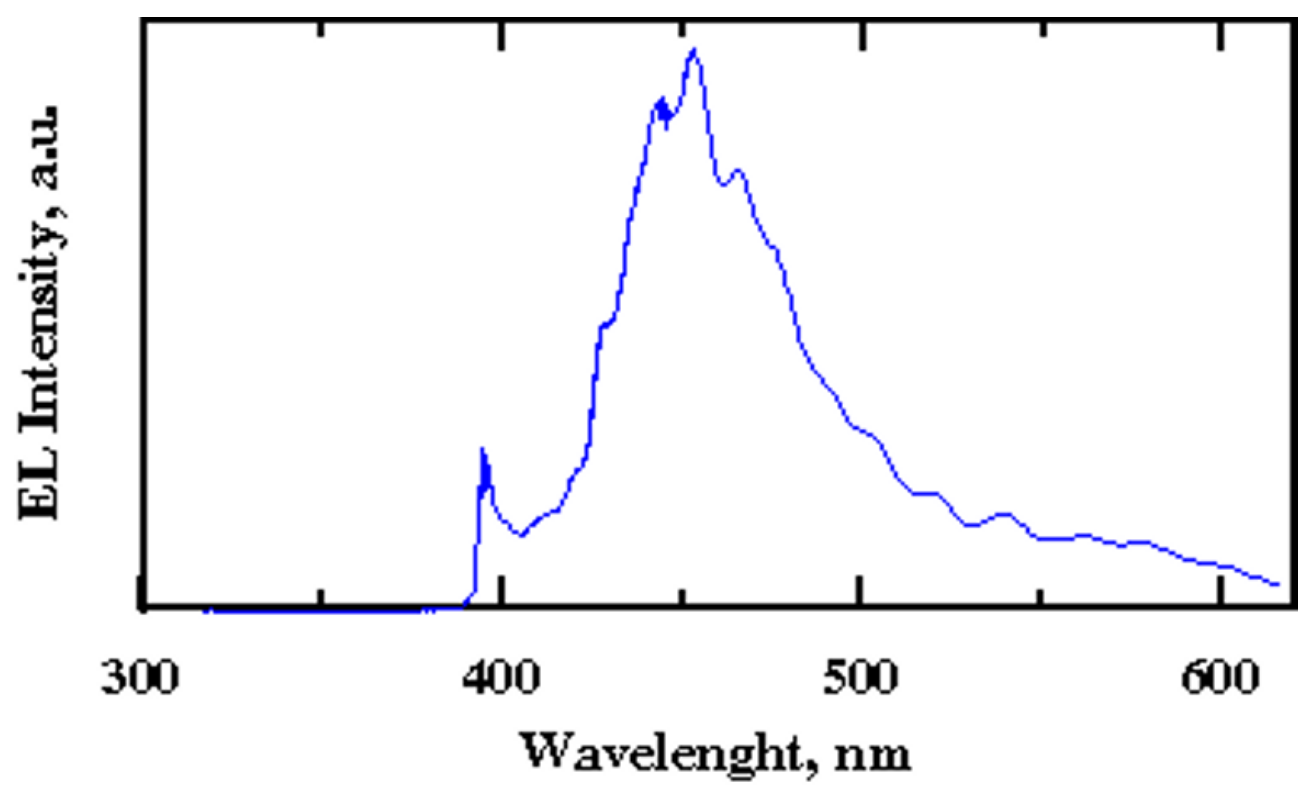

Figure 7. Electroluminescence spectra for a GaN p- n homojunction $\left(300 \mathrm{~K}, \mathrm{~J}=20 \mathrm{~A} / \mathrm{cm}^{2}\right.$ ).

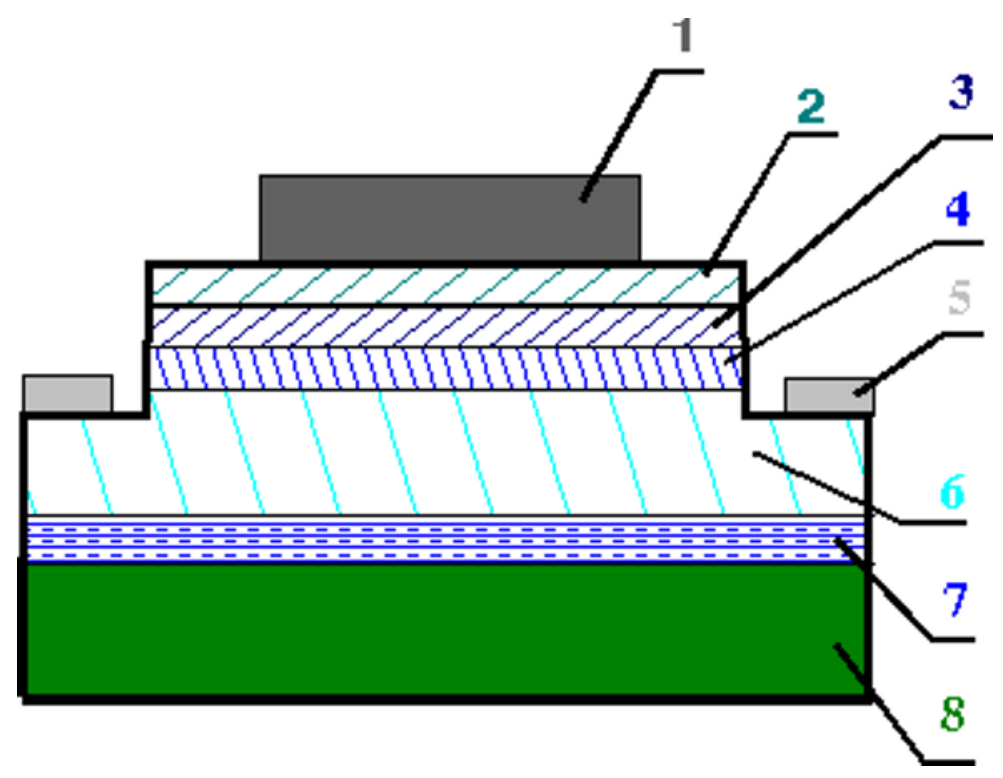

Figure 8a. Schematic drawing of the AlGaN p- $n$ junction structure: 1 - Pd contact to $p-G a N, 2$ p-GaN layer, 3 - p-AlGaN layer, 4 - n-AlGaN layer, 5 - Al contact to n-GaN, 6 - n-GaN layer, 7 -buffer layer, 8 - $6 \mathrm{H}-\mathrm{SiC}$ substrate. 


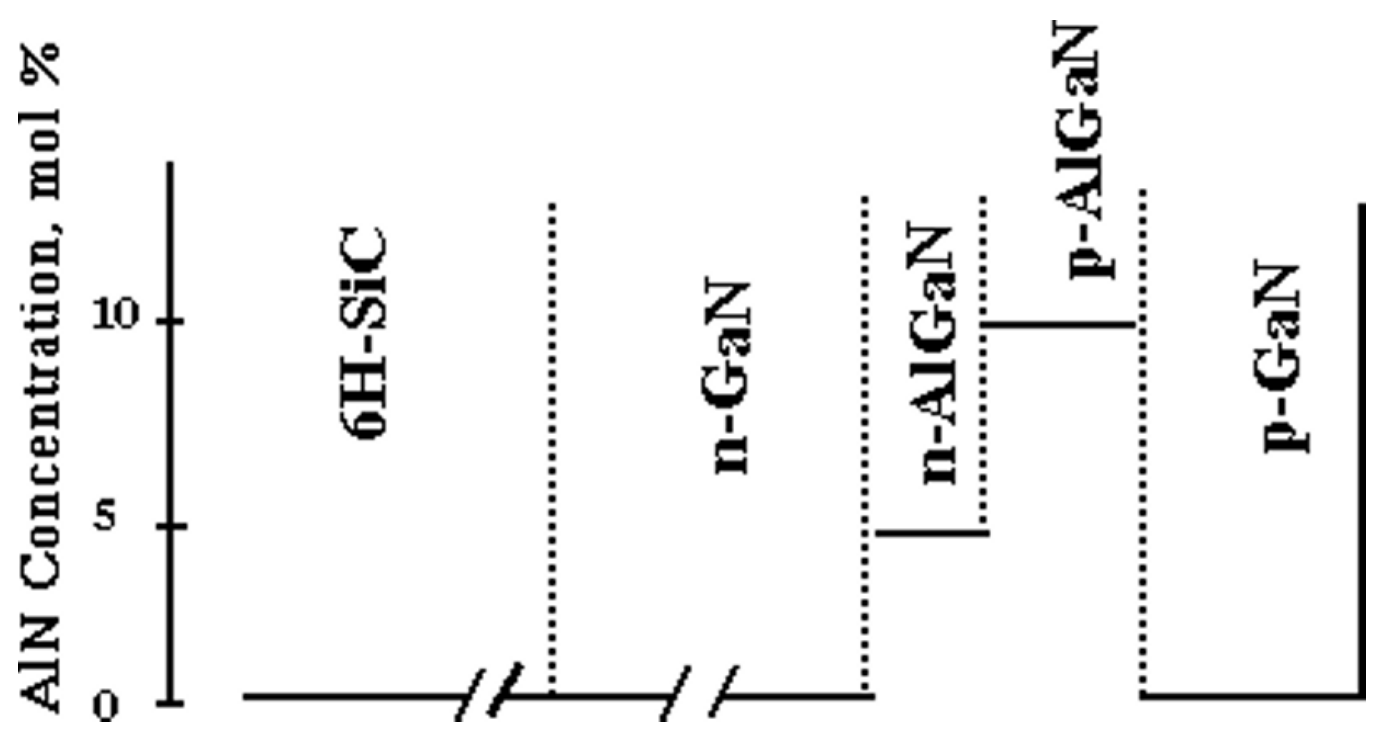

Figure 8b. Schematic drawing of the aluminium composition profile.

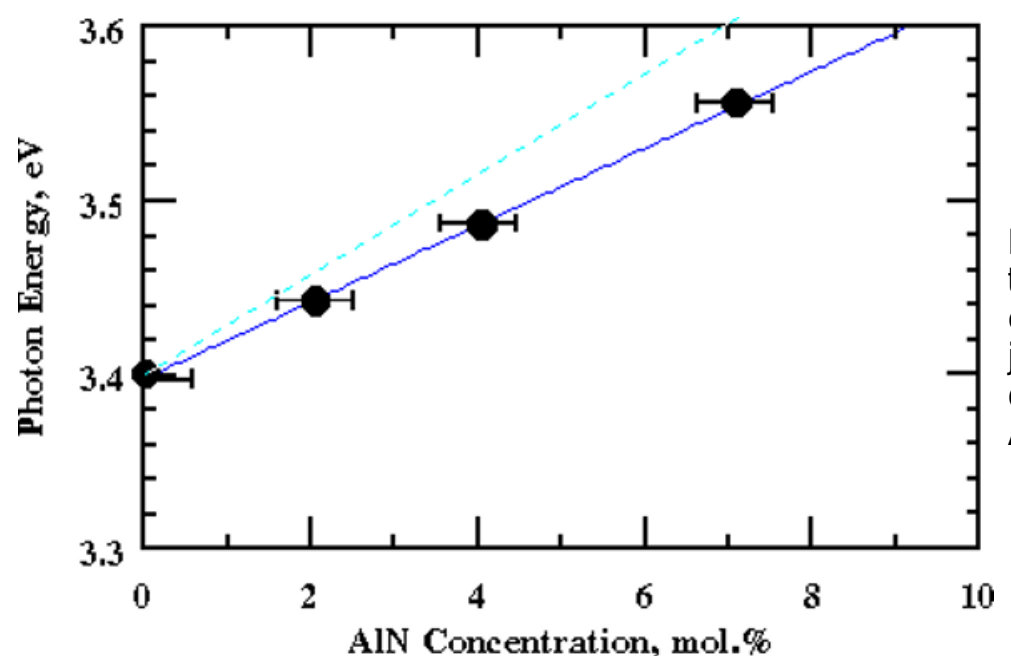

Figure 9. Dependence of the photon energy of the electroluminescence edge peak on AIN concentration in AlGaN (300 K) for AlGaN p- $n$ junction, dashed line is a linear approximation for direct bandgap - composition dependence for AlGaN alloys.

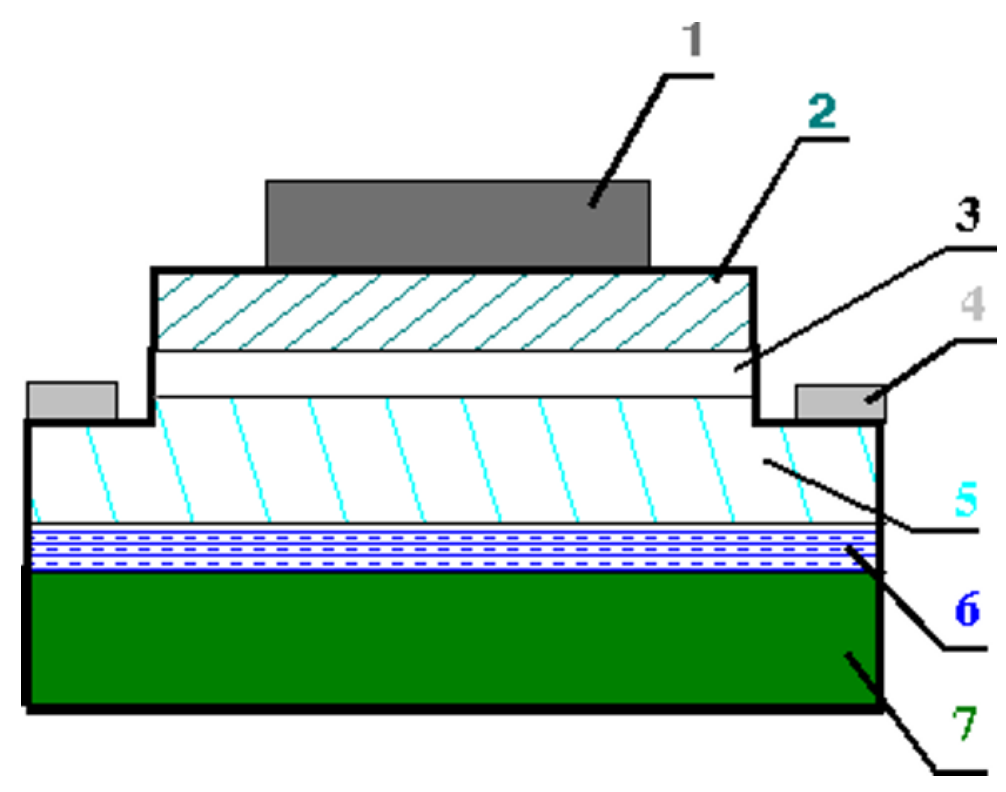

Figure 10. Schematic drawings of a GaN p-i-n structure: 1 - Pd contact to p-GaN, 2 - p-GaN layer, 3 - i-region, 4 - Al contact to n-GaN, 5 n-GaN layer, , 6 - buffer layer, 7 - 6H-SiC substrate. 


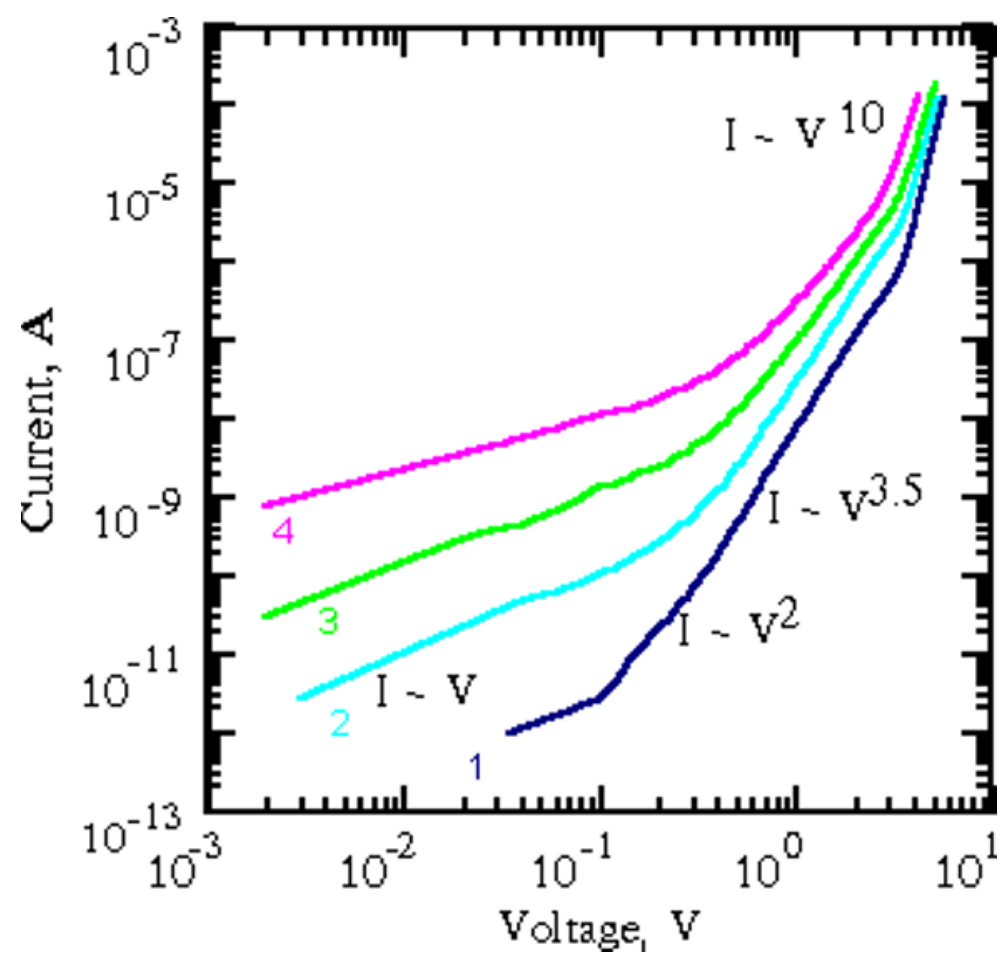

Figure 11. Forward I-V characteristics of a GaN p-i-n junction: 1 - 300 K, 2 - 400 K, 3 - 500 K, 4 $600 \mathrm{~K}$.

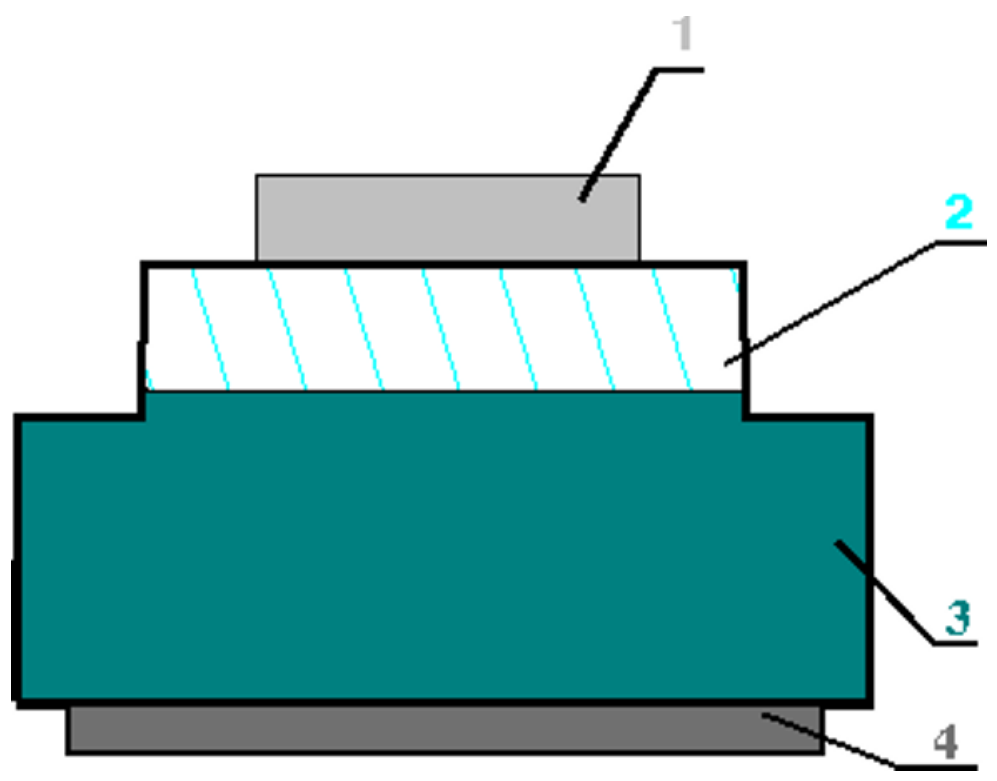

Figure 12. Schematic drawings of a GaN/SiC p- $n$ structure: 1 - Ti/Ni contact to n-GaN, 2 - n-GaN layer, 3 - p-6H-SiC substrate, 4 - contact to p-SiC. 


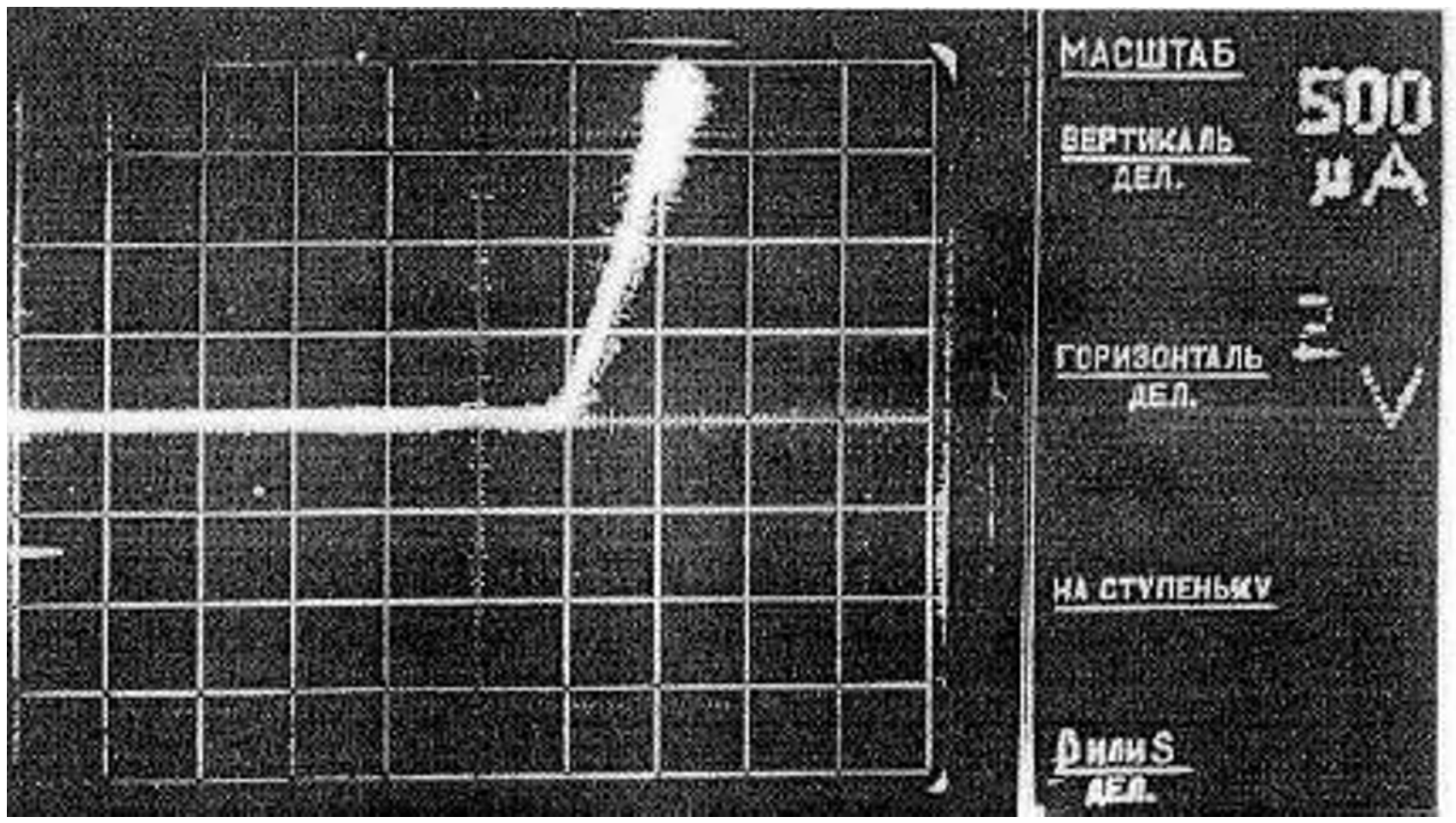

Figure 13. I-V characteristics of a GaN/SiC p- $n$ junction ( $300 \mathrm{~K}$ ): vertical scale - $0.5 \mathrm{~mA}$ /division, horizontal scale- 2 V/division.

C 1996-1997 The Materials Research Society

\begin{tabular}{|l|l|l|l|l|}
\hline $\mathrm{M}$ & $\mathrm{R}$ & $\mathrm{S}$ & Internet Journal of & Nitride Semiconductor Research \\
\hline
\end{tabular}

